OPEN ACCESS

Edited by:

Sudhir Gupta,

University of California, Irvine,

United States

Reviewed by:

Hans-Hartmut Peter,

University of Freiburg Medical Center,

Germany

Neil Romberg,

Children's Hospital of Philadelphia,

United States

Manisha Rajan Madkaikar,

National Institute of

Immunohaematology (ICMR), India

*Correspondence: Jacques J.M. van Dongen j.j.m.van_dongen@/umc.nı

Eduardo López-Granados elgranados@salud.madrid.org

Specialty section: This article was submitted to Primary Immunodeficiencies,

a section of the journal

Frontiers in Immunology

Received: 08 September 2020 Accepted: 29 December 2020 Published: 17 February 2021

Citation:

del Pino-Molina L, López-Granados E,

Lecrevisse Q, Torres Canizales J,

Pérez-Andrés $M$, Blanco E, Wentink $M$, Bonroy C, Nechvatalova J, Milota T,

Kienzler A-K, Philippé J, Sousa AE, van der Burg M, Kalina T,

van Dongen JJM and Orfao A (2021)

Dissection of the Pre-Germinal Center

$B$-Cell Maturation Pathway in

Common Variable Immunodeficiency

Based on Standardized Flow

Cytometric EuroFlow Tools.

Front. Immunol. 11:603972.

doi: 10.3389/fimmu.2020.603972

\section{Dissection of the Pre-Germinal Center B-Cell Maturation Pathway in Common Variable Immunodeficiency Based on Standardized Flow Cytometric EuroFlow Tools}

\author{
Lucía del Pino-Molina ${ }^{1}$, Eduardo López-Granados ${ }^{1 *}$, Quentin Lecrevisse ${ }^{2,3}$, \\ Juan Torres Canizales ${ }^{1}$, Martín Pérez-Andrés ${ }^{2,3}$, Elena Blanco ${ }^{2,3}$, Marjolein Wentink ${ }^{4}$, \\ Carolien Bonroy ${ }^{5}$, Jana Nechvatalova ${ }^{6}$, Tomas Milota $^{7}$, Anne-Kathrin Kienzler ${ }^{8}$, \\ Jan Philippé ${ }^{5}$, Ana E. Sousa ${ }^{9}$, Mirjam van der Burg ${ }^{10}$, Tomas Kalina ${ }^{11}$, \\ Jacques J.M. van Dongen ${ }^{12 *}$ and Alberto Orfao ${ }^{2,3}$ on behalf of the EuroFlow PID Consortium
}

\begin{abstract}
Clinical Immunology Department, La Paz University Hospital and Lymphocyte Pathophysiology in Immunodeficiencies Group, La Paz Institute for Health Research (IdiPAZ) and Center for Biomedical Network Research on Rare Diseases (CIBERER U767), Madrid, Spain, ${ }^{2}$ Clinical and Translation Research Program, Cancer Research Centre (IBMCC, USALCSIC), Department of Medicine, Cytometry Service (NUCLEUS), University of Salamanca (USAL), Institute of Biomedical Research of Salamanca (IBSAL), Salamanca, Spain, ${ }^{3}$ Biomedical Research Networking Centre Consortium of Oncology (CIBERONC) Instituto de salud Carlos III, Madrid, Spain, ${ }^{4}$ Department of Immunology, Erasmus University Medical Center (Erasmus MC), Rotterdam, Netherlands, ${ }^{5}$ Department of Laboratory Medicine, University Hospital Ghent, Ghent, Belgium, ${ }^{6}$ Department of Allergology and Clinical Immunology, Faculty of Medicine, Masaryk University and St Anne's University Hospital in Brno, Brno, Czechia, ${ }^{7}$ Department of Immunology, Second Faculty of Medicine, Charles University and Motol University Hospital, Prague, Czechia, ${ }^{8}$ Nuffield Department of Medicine, Experimental Medicine Division, University of Oxford, Oxford, United Kingdom, ${ }^{9}$ Instituto de Medicina Molecular, Faculdade de Medicina, Universidade de Lisboa, Lisboa, Portugal, ${ }^{10}$ Department of Pediatrics, Laboratory for Immunology, Leiden University Medical Center, Leiden, Netherlands, ${ }^{11}$ CLIP - Childhood Leukemia Investigation Prague, Department of Pediatric Hematology and Oncology, 2nd Faculty of Medicine, Charles University and University Hospital Motol, Praque, Czechia, ${ }^{12}$ Department of Immunohematology and Blood Transfusion, Leiden University Medical Center (LUMC), Leiden, Netherlands
\end{abstract}

Introduction: Common Variable Immunodeficiency (CVID) is characterized by defective antibody production and hypogammaglobulinemia. Flow cytometry immunophenotyping of blood lymphocytes has become of great relevance for the diagnosis and classification of CVID, due to an impaired differentiation of mature post-germinal-center (GC) classswitched memory B-cells (MBC) and severely decreased plasmablast/plasma cell (Pb) counts. Here, we investigated in detail the pre-GC B-cell maturation compartment in blood of CVID patients.

Methods: In this collaborative multicentric study the EuroFlow PID 8-color Pre-GC B-cell tube, standardized sample preparation procedures (SOPs) and innovative data analysis tools, were used to characterize the maturation profile of pre-GC B-cells in 100 CVID patients, vs 62 age-matched healthy donors (HD).

Results: The Pre-GC B-cell tube allowed identification within pre-GC B-cells of three subsets of maturation associated immature B-cells and three subpopulations of mature 
naïve B-lymphocytes. CVID patients showed overall reduced median absolute counts (vs $\mathrm{HD}$ ) of the two more advanced stages of maturation of both $\mathrm{CD} 5^{+} \mathrm{CD} 38^{+/++} \mathrm{CD} 21^{\text {het }}$ $\mathrm{CD}_{2} 4^{++}$(2.7 vs 5.6 cells $\left./ \mu \mathrm{l}, \mathrm{p}=0.0004\right)$ and $\mathrm{CD} 5^{+} \mathrm{CD} 38^{\text {het }} \mathrm{CD} 21^{+} \mathrm{CD} 24^{+}(6.5 \mathrm{vs} 17$ cells/ $\mu \mathrm{l}, \mathrm{p}<0.0001$ ) immature B cells (below normal HD levels in $22 \%$ and $37 \%$ of CVID patients). This was associated with an expansion of CD21 ${ }^{-} \mathrm{CD} 24^{-}$(6.1 vs $0.74 \mathrm{cells} / \mathrm{\mu l}$, $\mathrm{p}<0.0001$ ) and $\mathrm{CD} 21^{-} \mathrm{CD} 24^{++}$(1.8 vs 0.4 cells $/ \mu \mathrm{l}, \mathrm{p}<0.0001$ ) naïve $\mathrm{B}$-cell counts above normal values in $73 \%$ and $94 \%$ cases, respectively. Additionally, reduced lgMD ${ }^{+}(21$ vs 32 cells $/ \mu \mathrm{l}, \mathrm{p}=0.03$ ) and IgMD $^{-}$(4 vs 35 cells $/ \mu \mathrm{l}, \mathrm{p}<0.0001$ ) MBC counts were found to be below normal values in $25 \%$ and $77 \%$ of CVID patients, respectively, always together with severely reduced/undetectable circulating blood pb. Comparison of the maturation pathway profile of pre-GC B cells in blood of CVID patients vs HD using EuroFlow software tools showed systematically altered patterns in CVID. These consisted of: i) a normally-appearing maturation pathway with altered levels of expression of $>1$ (CD38, CD5, CD19, CD21, CD24, and/or smlgM) phenotypic marker (57/88 patients; 65\%) for a total of 3 distinct CVID patient profiles (group 1: 42/88 patients, 48\%; group 2: 8/88, 9\%; and group 3: $7 / 88,8 \%$ ) and ii) CVID patients with a clearly altered pre-GC B cell maturation pathway in blood (group 4: 31/88 cases, 35\%).

Conclusion: Our results show that maturation of pre-GC B-cells in blood of CVID is systematically altered with up to four distinctly altered maturation profiles. Further studies, are necessary to better understand the impact of such alterations on the post-GC defects and the clinical heterogeneity of CVID.

Keywords: CVID, Pre-GC B-cell tube, pre-GC maturation pathway, expression markers, EuroFlow standardization

\section{INTRODUCTION}

Common Variable Immunodeficiency (CVID) is the most prevalent symptomatic primary immunodeficiency (PID). It is characterized by defective antibody production that leads to hypogammaglobulinemia (1-3) with an increased susceptibility to infections, associated in some CVID patients with enteropathy, autoimmunity, lymphoproliferation, and/or risk of lymphoid malignancy due to more profound immunological dysregulation $(4,5)$. Despite distinct monogenic defects are present in a minor fraction $(<20 \%)$ of cases, and other complex oligo or polygenic genetic predisposition (6), and epigenetic alterations (e.g., impaired demethylation in genes relevant for the $\mathrm{B}$ cell functions) have been associated with the development of CVID (7), a well-defined pathogenic mechanism still remains to be identified in most CVID patients. Thus, assessment of the distribution of lymphocytes, particularly post-germinal center (GC) B-cells and plasmablasts/plasma

\footnotetext{
Abbreviations: APS, automated populations separator; BCR, B-cell receptor; BM, bone marrow; CVID, common variable immunodeficiency; ESID, European Society for Immunodeficiencies; FCS, flow cytometry standard; FSC, forward light scatter; GC, germinal center; HD, healthy donor; Ig, immunoglobulin; IUIS, International Union of Immunological Societies; MBC, memory B-cell; MFI, mean fluorescence intensity; $\mathrm{Pb}$, plasmablast/plasma cell; $\mathrm{PC}$, principal component; PCA, principal component analysis; PID, primary immune deficiency; sm, surface membrane; SOP, standard operating procedure; SSC, sideward light scatter; WBC, white blood cell.
}

cells in blood of suspicious patients by flow cytometry has become of great relevance for the diagnosis and classification of CVID $(8,9)$.

Impaired post-GC B cell maturation in the periphery (i.e., in blood and secondary lymphoid tissues) is a hallmark of CVID. However, CVID is a rather heterogeneous disease from the clinical, genetic and immunologic point of view. Thus, several classification algorithms have been proposed for CVID, which are based on the specific alterations encountered for the major $\mathrm{B}$ cell populations in blood (8), their proliferation history and somatic hypermutation levels (9), in combination or not with the clinical manifestations of the disease and/or more sophisticated computational (i.e., hierarchical clustering) approaches (10). Overall, impaired differentiation of mature post-GC B-cells, consisting of severely reduced circulating class-switched memory B-cells (MBC) and strongly decreased (i.e., undetectable) plasmablast/plasma cell production, are the most consistent defects in CVID. Because of this, demonstration of reduced class-switched MBC is now used among the diagnostic criteria proposed by the European Society for Immunodeficiencies (ESID) for CVID (11). In turn, depending on the specific defects encountered in the post-GC MBC and $\mathrm{Pb}$ compartments in blood, and the severity of such defects, distinct CVID patient subgroups, associated with distinct clinical profiles, have also been identified (12).

Apart from the alterations in post-GC B-cells and plasmablasts/plasma cells, an increasing number of evidences 
indicate that the production and maturation of B-cells in bone marrow (BM) is also altered in at least a fraction (e.g., around one third) of all CVID patients due to either a maturation blockade (13) and/or an altered bone marrow environment which is non-permissive for B-cell maturation (14). Thus, a significant proportion of CVID patients display reduced absolute B-cell counts in blood (5) and an early B-cell maturation arrest in $\mathrm{BM}$ (15). In addition, expansion of transitional/immature B cells, and CD $21^{\text {low }} \mathrm{B}$-cells has also been reported in a subset of CVID patients $(8,16)$. Altogether, these findings further support an impaired maturation of pre-GC B-cells in CVID.

Herein, we investigated in detail the pre-GC B-cell maturation compartment in blood of 100 CVID patients, taking advantage of the novel and standardized flow cytometric approaches developed by EuroFlow for this purpose (17-19), e.g., the recently proposed EuroFlow PID 8-color antibody panels (20) that can be easily implemented in most diagnostic laboratories worldwide, together with the EuroFlow standard operating procedures (SOPs) for sample preparation, data acquisition and analysis, including innovative data analysis tools recently developed by EuroFlow to assess normal vs altered pre-GC B-cell maturation profiles in blood (17, 20-23).

\section{MATERIAL AND METHODS}

\section{Patients, Controls, and Samples}

Overall, 100 adult CVID patients -50 men and 50 women; median age: 41 years (y); range: $16-82 y-$ and 62 healthy donors (HD) not related to the patients (33 men and 29 women; median age: $34 \mathrm{y}$; range: $19-67 \mathrm{y}$ ) were studied in parallel, at eight different EuroFlow-PID centers. CVID was diagnosed locally at each center, according to the ESID criteria $(3,24)$. Relevant clinical data on CVID patients was obtained from the patients' health electronic records or from national patient registries and collected at each of the 8 participating centers, including data on: patient age, gender, immunoglobulin (Ig) levels and response to vaccination at diagnosis, together with data on prior infections and type of infections (e.g., upper and lower bacterial respiratory infections, viral and fungal infections), autoimmunity (e.g., cytopenias, organ-based and systemic auto-immunity), lymphoproliferation, lymphoid interstitial pneumonitis (LIP), granulomas, splenomegaly, hepatomegaly, bronchiectasias, enteropathy, and malignancy, as well as prior therapy, including Ig replacement therapy.

Blood samples were obtained, processed and measured by flow cytometry at each of the 8 participating centers after informed consent had been given by each individual participant, according to the principles of the Declaration of Helsinki. The study was approved by the local Ethics Committees of the participating centers: Hospital Universitario La Paz, Madrid, Spain (PI-2833 and 2009/3348/I); Charles University, Prague, Czech Republic (15-28541A); Erasmus MC, Rotterdam, The Netherlands (MEC-2013-026); St Anne's University, Brno, Czech Republic (METC 1G2015); BRC-Translational Immunology Lab, University of Oxford, Oxford, United
Kingdom; University of Salamanca, Salamanca, Spain (USAL/ CSIC 20-02-2013); University Hospital of Ghent, Belgium (B670201523515); and Faculdade de Medicina da Universidade de Lisboa and Centro Hospitalar Universitário Lisboa Norte, Lisbon, Portugal (937/13).

\section{Flow Cytometric Identification of B-Cells, Plasmablasts/Plasma Cells and Their Subsets in Blood}

Blood samples from both CVID patients and HD were processed and stained at each center with the EuroFlow 8-color PIDOT and Pre-GC B-cell tubes, following the EuroFlow SOPs for staining of cell surface membrane $(\mathrm{sm})$ markers only, as previously described (20-22). Details about the specific antibody clones and fluorochrome-conjugated reagents used are provided in Supplementary Table 1 . Instrument set-up and calibration were performed prior to data acquisition on $\geq 1 \times 10^{6}$ cells (range: $1 \times 10^{6}-5 \times 10^{6}$ cells) in FACSCanto II flow cytometers -Becton/Dickinson Biosciences (BD), San José, CA-, following the EuroFlow SOPs available at www.EuroFlow.org (21). Data analysis was performed centrally on pseudoanonymazed flow cytometry standard (FCS) data files deposited in the EuroFlow data repository, using the Infinicyt software (Cytognos SL, Salamanca, Spain).

For data analysis, a standardized gating strategy was used for identification of all pre-GC (defined as $\mathrm{CD} 19^{+} \mathrm{CD}^{-} 7^{-} \mathrm{sIgM}^{+} \mathrm{B}-$ lymphocytes) and post-GC B-cell subsets (defined as $\mathrm{CD}^{+} 9^{+}$ $\mathrm{CD} 27^{+}$or $\mathrm{CD}_{19}{ }^{+} \mathrm{CD}^{-} 7^{-}$smIgM $^{-} \mathrm{B}$-cells) present in blood, based on the EuroFlow-PID Pre-GC B cell tube as illustrated in Supplementary Figure 1. Briefly, CD $19^{+}$B-cells and plasmablasts/plasma cells were both identified by their low-tointermediate forward (FSC) and sideward (SSC) light scatter properties after excluding debris and cell doublets. Subsequently, both cell subsets were sub-classified into 11 different subsets based on their staining profile for CD19, CD38, CD24, CD21, CD27, CD5, smIgM, and smIgD: a) CD27 CD $38^{\text {hi }} \mathrm{CD} 24^{\text {hi }} \mathrm{CD}^{+}$ smIgM ${ }^{++} \mathrm{D}^{+}$immature/transitional $\mathrm{B}$ cells; b) $\mathrm{CD}^{-} \mathrm{CD}^{-} 8^{-}$ $\mathrm{CD} 24^{\text {het }} \mathrm{CD} 5^{\text {het }} \mathrm{smIgM}^{+} \operatorname{IgD}^{++}$mature naive B lymphocytes; c) $\mathrm{CD} 27^{+} \mathrm{CD}^{\mathrm{lo}} 8^{\mathrm{CD}} 5^{-} \mathrm{CD} 24^{\text {het }} \mathrm{smIgM}^{++} \mathrm{D}^{+}\left(\mathrm{MD}^{+}\right)$unswitched MBCs; d) $\mathrm{CD}_{27^{+/-}} \mathrm{CD} 38^{\text {lo }} \mathrm{CD} 5^{-} \mathrm{CD} 24^{\text {het }} \operatorname{smIgM}^{-} \mathrm{D}^{-}\left(\mathrm{MD}^{-}\right)$ switched MBCs; and, e) $\mathrm{CD} 27^{++} \mathrm{CD} 38^{\text {hi }} \mathrm{CD} 5^{-} \mathrm{CD} 21^{-} \mathrm{CD} 24^{-}$ plasmablasts/PCs. Immature/transitional B cells were further sub-classified according to the pattern of expression of CD38, CD5, CD21, and CD24 into three subsets of increasingly more mature B-lymphocytes: a1) $\mathrm{CD}^{-} \mathrm{CD} 38^{++} \mathrm{CD} 21^{\text {het }} \mathrm{CD} 24^{++}$; a2) $\mathrm{CD}^{+} \mathrm{CD} 38^{+++} \mathrm{CD} 21^{\text {het }} \mathrm{CD} 24^{++}$, and a3) $\mathrm{CD} 5^{+} \mathrm{CD} 38^{\text {het }} \mathrm{CD} 21^{+}$ $\mathrm{CD} 24^{+}$immature/transitional B lymphocytes. In turn, mature naive B-lymphocytes and unswitched MBCs were also further sub-classified into three subsets each, based on the expression profile for CD21 and CD24, into CD $21^{+} \mathrm{CD} 24^{+}, \mathrm{CD} 21^{-} \mathrm{CD} 24^{++}$, and $\mathrm{CD} 21^{-} \mathrm{CD} 24^{-}$mature naïve $\mathrm{B}$ cells and unswitched $\mathrm{MBC}$, respectively.

For each B cell population, absolute counts were calculated using a dual platform assay based on the white blood cell (WBC) count, as assessed in a conventional hematological cell counter, and the percentage of total B cells obtained with the PIDOT tube 
for the same sample, as previously reported (22). Normal reference ranges were defined by the $5^{\text {th }}$ and $95^{\text {th }}$ percentile values observed in blood of 62 (age- and sex-matched) HD analyzed in parallel to the CVID patients (Supplementary Table 2).

\section{Pre-GC B-Cell Maturation Pathway in Blood}

A database reflecting the normal B-cell maturation pathway of pre-GC B-lymphocytes in blood was built by merging data files from 18 representative $\mathrm{HD}$, using the Infinicyt software (Cytognos SL) and previously described procedures (25). For this purpose, pre-gated data files which specifically contained gated data exclusively on the three different subsets of immature blood B cells $\left(\mathrm{CD}^{-} \mathrm{CD} 38^{++} \mathrm{CD} 21^{\text {het }} \mathrm{CD} 24^{++}, \mathrm{CD}^{+} \mathrm{CD} 38^{+/++}\right.$ $\mathrm{CD} 21^{\text {het }} \mathrm{CD} 24^{++}$and $\mathrm{CD} 5^{+} \mathrm{CD} 38^{\text {het }} \mathrm{CD} 21^{+} \mathrm{CD} 24^{+}$immature B cells), together with both the $\mathrm{CD} 21^{+} \mathrm{CD} 24^{+}$and $\mathrm{CD} 21^{-} \mathrm{CD} 24^{-}$ mature naive $\mathrm{B}$ cell subsets, from blood of $18 \mathrm{HD}$ stained with the Pre-GC B-cell tube were merged into a single data file. Mature naive $\mathrm{CD} 21^{-} \mathrm{CD} 24^{++} \mathrm{B}$ cells were not included in the pre-GC Bcell database since this subset is barely detectable in normal blood from HD (26). Then, the merged data file was used to define the maturation pathway of pre-GC B-cells using the maturation tool developed by EuroFlow and implemented in Infinicyt (v2.0-4b for EuroFlow members only). This tool allows for automatic i) definition of vectors that reflect maturation pathways based on curve analysis algorithms, ii) classification of events into different maturation stages arbitrarily set at equal distances, iii) calculation of descriptive statistics for all events classified within each maturation stage, followed by direct visualization in a (balanced) 3-dimension (3D) APS (automated population separator) diagram, constructed using the first three principal components (PC1 to PC3) derived from $\mathrm{PC}$ analysis (PCA) performed with the Infinicyt software (Figure 1A). Thus, based on the maturation tool of the Infinicyt software, 10 distinct pre-GC B-cell maturation stages were (arbitrarily) defined and the normal mean fluorescence intensity (MFI) range (2SD) per maturation stage was calculated for each individual

A

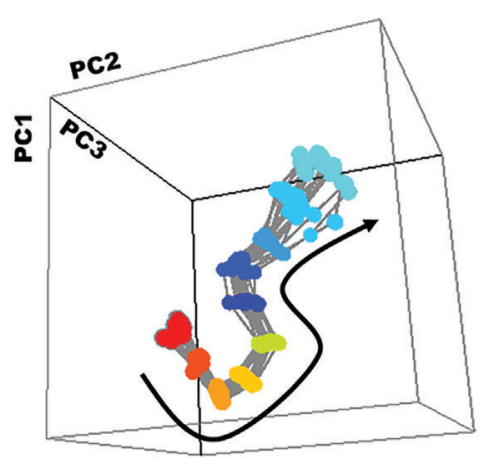

Maturation stages

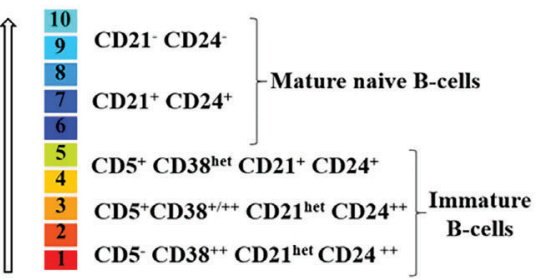

B
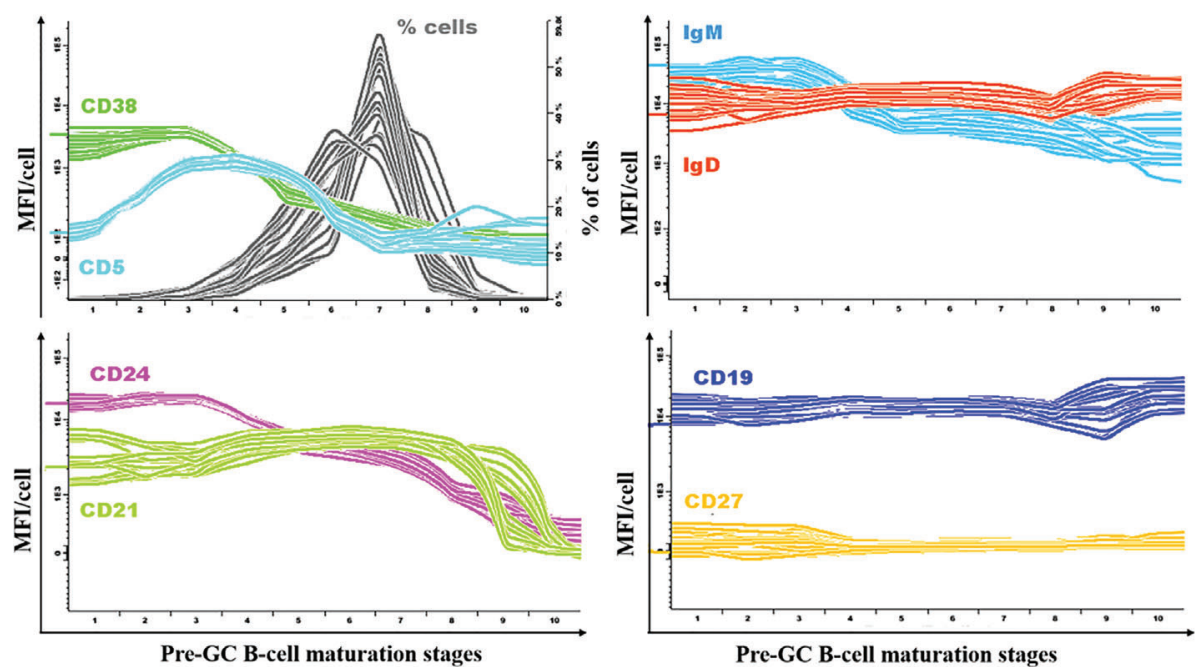

FIGURE 1 | Illustrating example of the normal (reference) pre-germinal-center (GC) maturation pathway. Overall phenotypes (A) and expression levels for individual markers per stage of maturation (B) are shown for each individual donor $(n=18)$ included in the normal reference pre-GC B-cell maturation pathway used to define reference normal values, depicted as color-coded lines per marker/parameter. 
cell surface marker. Afterward, deconvolution of the maturation vector defined by the median MFI values per maturation stage $(n=10)$ data was plotted for the whole set of phenotypic markers included in the EuroFlow Pre-GC B-cell tube (Figure 1A). Subsequently, median (range) and mean (+2 SD) fluorescence intensity (MFI) values per marker in HD blood pre-GC B-cells together with the corresponding B cell percentage, were plotted along the different maturation stages and used as normal reference range (Figure 1B). Subsequently, gated pre-GC Bcells from every individual CVID case were plotted against the normal reference maturation database and differences in MFI values vs. the normal blood range were recorded per marker for each of the 10 pre-established pre-GC B-cell maturation stages. MFI values below $2 \mathrm{SD}$ or above $2 \mathrm{SD}$ of the normal reference range (per maturation stage) for at least two consecutive stages of maturation of pre-GC B-cells, were considered to be altered. In parallel, a graphical display of the values per marker along the pre-GC B-cell maturation pathway, in which each patient is represented against the database, was obtained.

\section{Statistical Analyses}

Statistical analyses were performed with GraphPad Prism Software version 6.0 (Graph- Pad software, San Diego, CA). To define normal ranges for each $B$ cell subset identified in blood, $5^{\text {th }}$ and $95^{\text {th }}$ percentile values from the 62 adult HD were used. Group comparisons were performed using the Mann-Whitney $U$ and Kruskal-Wallis tests (for continuous variables) or the Fisher exact and $\mathrm{X}^{2}$ tests (for categorical variables). Clustering analysis based on K-means was performed using the JMP software (free trial version 14; SAS Institute Inc., Cary, NC) based on the immunophenotypic profiles and relative distributions of pre-GC B-cells along the pre-GC maturation pathway, per maturation stage. Cluster analysis was performed by simultaneously comparing the MFI values for each surface marker and the percentage of events per stage of maturation per CVID patient against the maturation reference database. $\mathrm{P}$-values $<0.05$ were considered to be associated with statistical significance and coded hereafter as follows: ${ }^{\star} \mathrm{p}$-value $<0.05 ;{ }^{*} \mathrm{p}$-value $<0.01$; ${ }^{* *} \mathrm{p}$ value $<0.001$; and, ${ }^{\star * * *} \mathrm{p}$-value $<0.0001$.

\section{RESULTS}

\section{Distribution of Pre-GC B-Cell Subsets in Blood of CVID Patients}

Based on the data provided by the PID-orientation tube (PIDOT) (22), and the Pre-GC B-cell tube, detailed characterization of B cells in peripheral blood was achieved for a total of 11 distinct $B$ cell subsets: i) immature/transitional B-cells (including three maturation-associated populations of $\mathrm{CD}^{-} \mathrm{CD}^{-++} \mathrm{CD} 21^{\text {het }}$ $\mathrm{CD} 24^{++}, \mathrm{CD}^{+} \mathrm{CD} 38^{+/++} \mathrm{CD} 21^{\text {het }} \mathrm{CD} 24^{++}$, and $\mathrm{CD} 5^{+}$ $\mathrm{CD} 38^{\text {het }} \mathrm{CD} 21^{+} \mathrm{CD} 24^{+}$immature B-cells); ii) mature naïve $\mathrm{B}$ cells (and their three $\mathrm{CD} 21^{+} \mathrm{CD} 24^{+}, \mathrm{CD} 21^{-} \mathrm{CD} 24^{++}$, and CD $21^{-}$ $\mathrm{CD} 24^{-}$subsets); iii) unswitched $\operatorname{IgMD}^{+}, \operatorname{IgM}^{+}$-only, and $\operatorname{IgD}^{+}$ -only MBC (and their CD $21^{+} \mathrm{CD} 24^{+}, \mathrm{CD} 21^{-} \mathrm{CD} 24^{-}$, and CD21
$\mathrm{CD}^{2} 4^{++}$subsets); iv) switched IgMD ${ }^{-} \mathrm{MBC}$; and v) plasmablasts/ plasma cells (Figures 2A-C).

Overall, the total B-cell count in blood of CVID was significantly reduced vs. age-matched HD (median: 149 vs 206 cells/ $\mu \mathrm{l} ; \mathrm{p}=0.04$ ). Such decrease was mostly due to a significant reduction of immature B-cells ( 11 vs 27 cells/ $\mu \mathrm{l}, \mathrm{p}<0.0001$ ), IgMD ${ }^{+} \mathrm{MBC}$ ( 21 vs 32 cells $/ \mu \mathrm{l}$, $\mathrm{p}=0.03$ ) and particularly, IgMD ${ }^{-}$MBC counts (4 vs 35 cells $/ \mu \mathrm{l}$, $\mathrm{p}<0.0001)$, in the absence of virtually no plasmablasts/plasma cells (Figure 3A). Despite the overall reduced median B-cell counts observed in CVID, a significant overlap with HD was still observed with variable frequencies and patterns of alteration among CVID patients. Thus, decreased counts below normal values $\left(<5^{\text {th }}\right.$ percentile of age-matched $\mathrm{HD}$ ) of IgMD $\mathrm{IgBC}^{-}$were detected in $77 \%$ of the CVID patients investigated, together with undetectable plasmablasts/plasma cells in $100 \%$ of cases. In contrast, reduced immature/transitional B cells and IgMD ${ }^{+}$MBC counts were only found in $29 \%$ and $25 \%$ of cases, respectively (Figure 3A). In turn, only a small percentage of all CVID patients showed reduced mature naïve B-cell counts (11\%). Altogether, the decreased numbers of the distinct B-cell subsets led to overall low total Bcell counts in blood of $21 \%$ of all CVID patients (Figure 3A).

More detailed analysis of the pre-GC B-cell compartment also showed distinct patterns of alteration for different subsets of immature B-cells and mature naive B-cells. Thus, reduced counts (vs age-matched HD) of the more advanced stages of maturation of $\mathrm{CD}^{+} \mathrm{CD} 8^{+++} \mathrm{CD} 21^{\text {het }} \mathrm{CD} 24^{++}(2.7$ vs $5.6 \mathrm{cells} / \mu \mathrm{l}$, $\mathrm{p}=0.0004)$ and $\mathrm{CD}^{+} \mathrm{CD}^{+} 8^{\text {het }} \mathrm{CD} 21^{+} \mathrm{CD} 24^{+}$(6.5 vs 17 cells/ $\mu \mathrm{l}, \mathrm{p}<0.0001)$ immature/transitional B cells was detected in $22 \%$ and $37 \%$ of CVID patients. In contrast, the less differentiated $\mathrm{CD}^{-} \mathrm{CD} 8^{++} \mathrm{CD} 21^{\text {het }} \mathrm{CD} 24^{++}$immature/transitional $\mathrm{B}$ lymphocytes ( 0.79 vs $0.89, \mathrm{p}>0.05)$ were decreased in blood in only $7 \%$ of CVID patients (Figure 3B). Regarding mature naive $\mathrm{B}-$ cells, an increase in $\mathrm{CD}^{2} 1^{-} \mathrm{CD} 24^{-}(6.1 \mathrm{vs} 0.74 \mathrm{cells} / \mu \mathrm{l}$, $\mathrm{p}<0.0001)$ and $\mathrm{CD} 21^{-} \mathrm{CD} 24^{++}(1.8$ vs 0.4 cells $/ \mu \mathrm{l}, \mathrm{p}<0.0001)$ naive $B$ cell counts was observed in CVID vs. HD, with a clear bimodal distribution (Figure 3B) due to the presence of a major subgroup of patients ( $73 \%$ and $94 \%$, respectively) presenting a significant expansion of these two naive B-cell subsets, in association or not with low CD $21^{+} \mathrm{CD} 24^{+}$naïve B-cell counts, which were found to be reduced in only $21 \%$ of CVID patients (Figure 3B).

Regarding post-GC MBC, CVID patients displayed a significant reduction (vs. HD) of $\mathrm{CD} 21^{+} \mathrm{CD} 24^{+} \mathrm{IgMD}^{+} \mathrm{MBC}$ (16 vs 31 cells/ $\mu \mathrm{l}, \mathrm{p}=0.0006$ ), associated with normal or slightly increased $(\mathrm{p}>0.05) \mathrm{CD}_{2} 1^{-} \mathrm{CD} 24^{-}$and CD21 ${ }^{-} \mathrm{CD} 24^{++} \mathrm{IgMD}^{+}$ MBC numbers (Supplementary Figure 2). Plasmablasts/ plasma cells, were either not detected or severely reduced in $100 \%$ of CVID patients. Altogether, these results suggest the existence of different maturation blockades and profiles in CVID, which frequently also involve pre-GC B-cells, in addition to postGC MBC and plasmablasts/plasma cells.

\section{Pre-GC B-Cell Maturation Profile in Normal Blood}

Based on the innovative maturation tools developed by EuroFlow (18, 25), a normal pre-GC B-cell reference 
A

Gated B-cells and plasmablasts

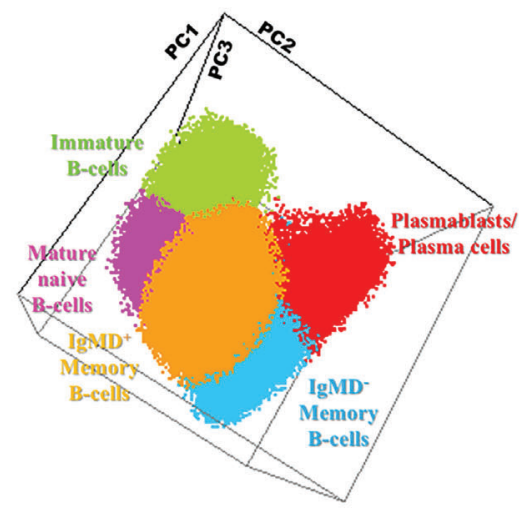

B

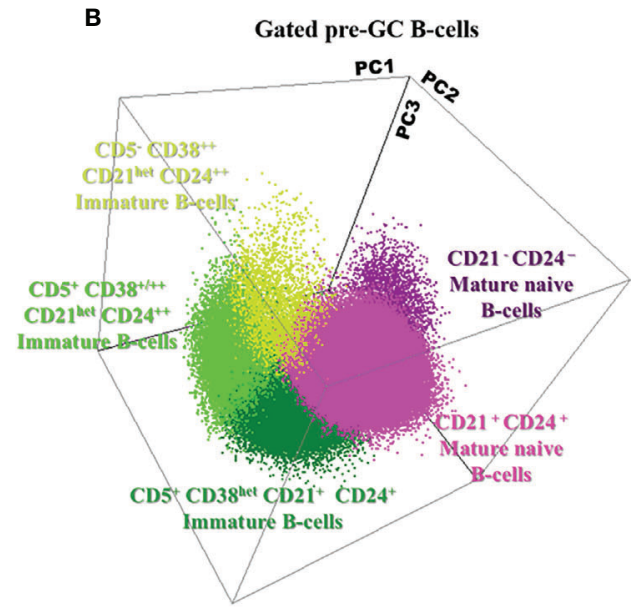

C

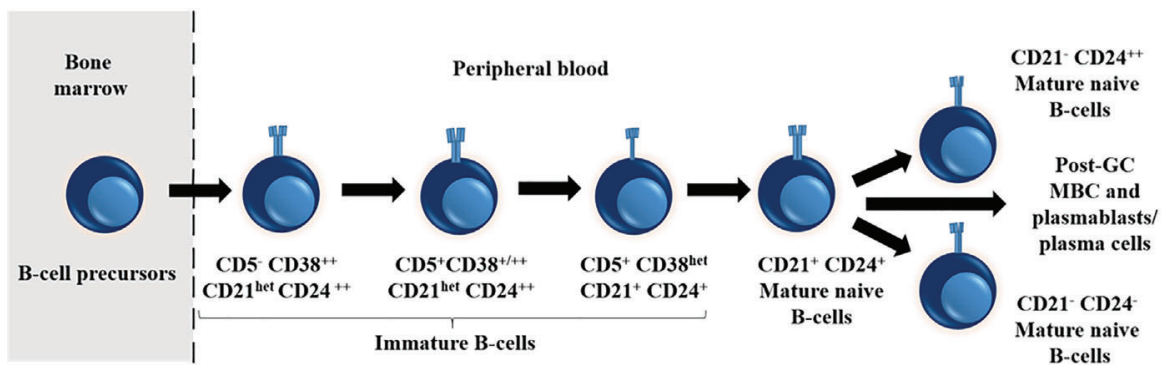

FIGURE 2 | Distribution of the major subsets of immature, naive and memory B cells (MBC) and plasmablasts/plasma cells (A), including the different subsets of pre-germinal-center (GC) B-cells (B), in blood of a representative adult healthy donor (HD) and their maturation-associated relationship (C). Three-dimensional principal component (PC) analysis (PCA) plots in (A, B) were built based on PC1 (A: mean fluorescence intensity of CD27, 29.25\%; IgD, 22.56\%; IgM, 20.45\%; CD21, 11.16\%; CD38, 9.63\% and CD5, 6.95\%; B: mean fluorescence intensity of CD21, 30.15\%; CD24, 27.64\%; CD38, 23.07\% and CD5, 19.14\%), PC2 (A: mean fluorescence intensity of IgM, 43.89\%, CD27, 34.62\%, CD38, 10.18\%, IgD, 9.96\%; CD21, 1.16\% and CD5, 0.18\%; B: mean fluorescence intensity of CD21, 43.66\%, CD38, 23.62\%, CD24, 17.09\% and CD5, 15.63\%) and PC3 (A: mean fluorescence intensity of CD38, 42.02\%, CD21, 19.56\% CD27, 12.19\%, CD5, $12.03 \%$, IgD, $11 \%$ and $\operatorname{lgM}, 3.20 \%$; B: mean fluorescence intensity of CD5, 56.16\%, CD24, 27.80\%, CD38, 14.85\% and CD21, 1.19\%) vectors using the (balanced) automated population separator (APS1-2) 3-D view of Infinicyt. In both (A, B), the distinct color-coded cell populations displayed were gated as described in Supplementary Figure 1.

maturation pathway was built as described above in the material an methods section and illustrated in Figure 1A.

Detailed analysis of the normal pre-GC B-cell maturation profile showed downregulation of CD38 from stage 3 on, associated with strong CD5 and CD24 expression at early stages (stages 2-4 and stages 1-3, respectively), CD5 becoming negative from stage 7 onwards while CD24 progressively decreased from stage 4 onward; in turn, CD21 was strongly expressed from stage 1 until the last stages of maturation (stages 9 and 10), when it was downregulated. Among the other markers investigated, smIgM showed slightly higher expression levels at early (stages 1-3) vs later stages with stable levels from stage 4 to 10 , while IgD and CD19 showed similarly stable expression levels along all stages of maturation of pre-GC B-cells. By definition CD27 was not expressed in pre-GC B-cells (Figure 1B).

\section{Altered Maturation Profiles of Blood Pre-GC B-Cells in CVID}

Direct comparison of the phenotype of maturation-associated blood pre-GC B-cell subsets from CVID patients vs. the normal maturation was performed in 88 patients by plotting phenotypic data from each CVID against the normal reference maturation database (Figures 4 and 5). For better visualization of the phenotypic deviations from normal, a normalized scale (Supplementary Figure 3) was used. Overall, distinct patterns of alteration (cell counts and/or MFI values per marker in $\geq 2 / 10$ consecutive stages of maturation of pre-GC B-cells falling $\geq 2 \mathrm{SD}$ apart from the normal distribution) of the pre-GC B-cell maturation were detected in every case $(88 / 88 ; 100 \%)$. Thus, four distinct patterns of alterations were identified: a) CVID with normally-appearing maturation pathways (groups 1 to 3 ) but 
A

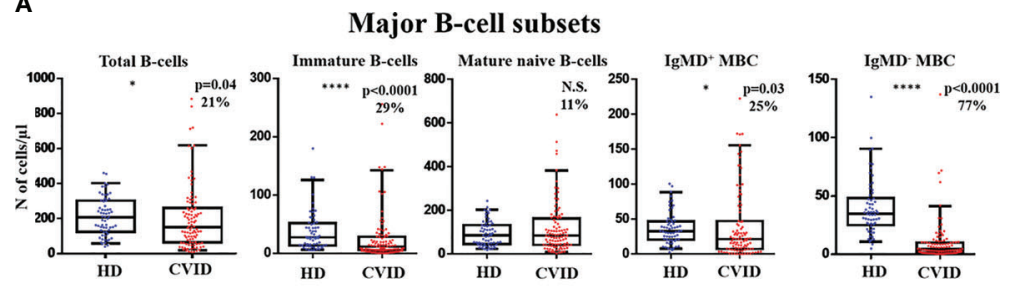

B

Immature B-lymphocyte subsets
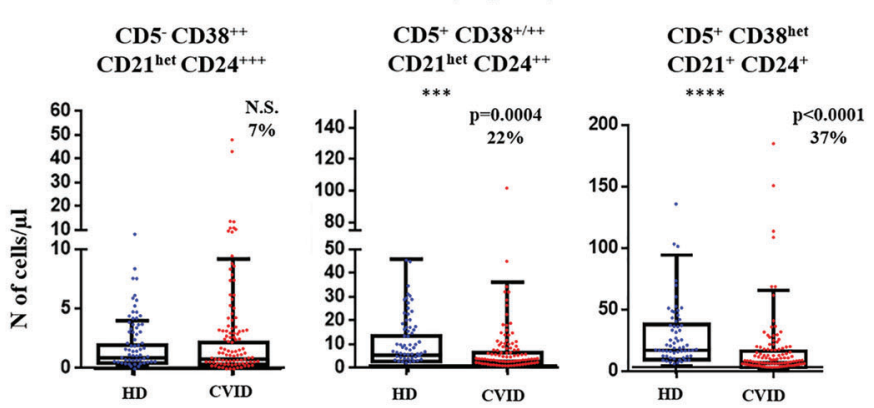

Mature naive B-lymphocyte subsets

$\mathrm{CD}^{+}{ }^{+\mathrm{CD}^{+}}{ }^{+}$

CD21- CD24-

$\mathrm{CD}^{-} \mathrm{CD}^{-} 4^{++}$
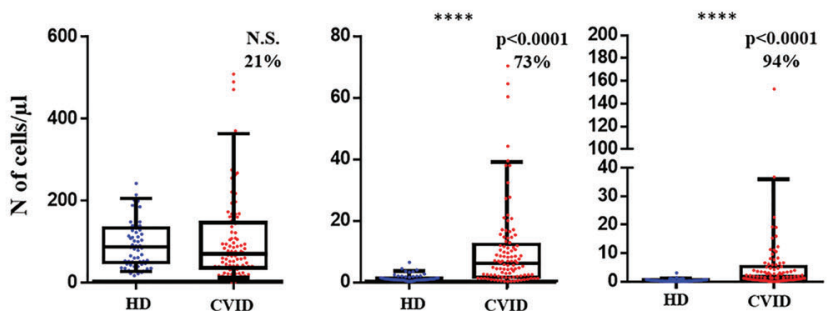

FIGURE 3 | Distribution of distinct subsets of pre-germinal-center (GC) and post-GC B-cells in blood of Common Variable Immunodeficiency (CVID) patients ( $\mathrm{n}=100$ ) vs age-matched $\mathrm{HD}(\mathrm{n}=62)$. (A) absolute counts of major pre-GC and post-GC B-cell subsets are shown using box and whiskers plots separately for healthy donor $(H D)(n=62)$ and CVID patients $(n=100)$ where horizontal lines and vertical lines represent the median and both $5^{\text {th }}$ and $95^{\text {th }}$ percentile values, respectively.

Percentage of CVID patients with decreased or increased counts below or above normal values ( $<5^{\text {th }}$ and $>95^{\text {th }}$ percentile) detected in age-matched HD are shown as percent values. (B) absolute pre-GC CD5 $\mathrm{CD}^{-1+} \mathrm{CD} 21^{\text {het }} \mathrm{CD} 24^{+++}, \mathrm{CD}^{+} \mathrm{CD} 38^{+/++} \mathrm{CD} 21^{\text {het }} \mathrm{CD} 24^{++}$, and $\mathrm{CD} 5^{+} \mathrm{CD} 38^{\text {het }} \mathrm{CD} 21^{+} \mathrm{CD} 24^{+}$immature B-cell and $\mathrm{CD} 21^{+} \mathrm{CD} 24^{+}, \mathrm{CD} 21^{-} \mathrm{CD} 24^{-}$, and $\mathrm{CD} 21^{-} \mathrm{CD} 24^{++}$naiive B-cell subset counts in CVID vs HD. N.S. not statistically significant differences detected, ${ }^{*} \mathrm{p}-$ value $<0.05$;

${ }^{* * *}$ p-value $<0.001 ;{ }^{* * \star *}$-value $<0.0001$ (Mann Whitney $U$ test).

distinct patterns of alteration on the levels of expression of individual phenotypic markers $(57 / 88,65 \%)$ and b) CVID patients with a clearly altered pre-GC B-cell maturation pathway (31/88 cases, 35\%; CVID group 4) (Figures 4A and B). In turn, unsupervised clustering analysis further revealed the presence of three different profiles among the former CVID patient groups 1 to 3 , depending on the pattern of deviation in the number of cells per maturation stage and the levels of expression of individual markers, from the normal reference maturation pathway (Figure 5 and Supplementary Figure 3).

In group 1 a large fraction of CVID patients $(42 / 88,48 \%)$ was included, who showed significantly reduced total B-cell (128 vs 206 cells $/ \mu \mathrm{l}, \mathrm{p}=0.008)$ and both $\mathrm{CD}^{+} \mathrm{CD} 38^{+/++} \mathrm{CD} 21^{\text {het }} \mathrm{CD} 24^{++}$ (2.6 vs 5.6 cells $/ \mu \mathrm{l}, \mathrm{p}=0.0013$ ) and $\mathrm{CD}^{+} \mathrm{CD} 38^{\text {het }} \mathrm{CD} 21^{+} \mathrm{CD} 24^{+}$ (7.3 vs 17 cells/ $\mu \mathrm{l}, \mathrm{p}<0.0001$ ) immature/transitional $\mathrm{B}$-cell numbers, in the absence of overall relevant phenotypic deviations from the normal maturation profile of blood preGC B-cells (Supplementary Figure 3). Group 2 consisted of 8/88 (9\%) CVID patients that showed overexpression of smIgM at intermediate stages of maturation of pre-GC B-cells and of CD38 at early and late stages of maturation of pre-GC B-cells; compared to HD, CVID cases classified in group 2 also showed significantly higher counts of the most immature $\mathrm{CD} 5$ $\mathrm{CD} 38^{++} \mathrm{CD} 21^{\text {het }} \mathrm{CD} 24^{++}$(7.6 vs 0.89 cells/ $\mu \mathrm{l}, \mathrm{p}=0.0009$ ) pre-GC $\mathrm{B}$-cell subset, associated with reduced numbers of more differentiated $\mathrm{CD}^{+}{ }^{+} \mathrm{CD} 38^{\text {het }} \mathrm{CD} 21^{+} \mathrm{CD}_{2} 4^{+}$immature $\mathrm{B}$ lymphocytes (5.1 vs 17 cells $/ \mu \mathrm{l}, \mathrm{p}=0.0183)$ and $\mathrm{IgMD}^{+}$ (particularly $\mathrm{CD} 21^{+} \mathrm{CD} 24^{+}$) MBC (4 vs 31 cells/ $\mu \mathrm{l}, \mathrm{p}<0.0001$ ); in addition, group 2 patients also showed decreased levels of CD21 at stages $7-8$, reflecting the parallel increase in $\mathrm{CD}_{21}^{-}$ 
A
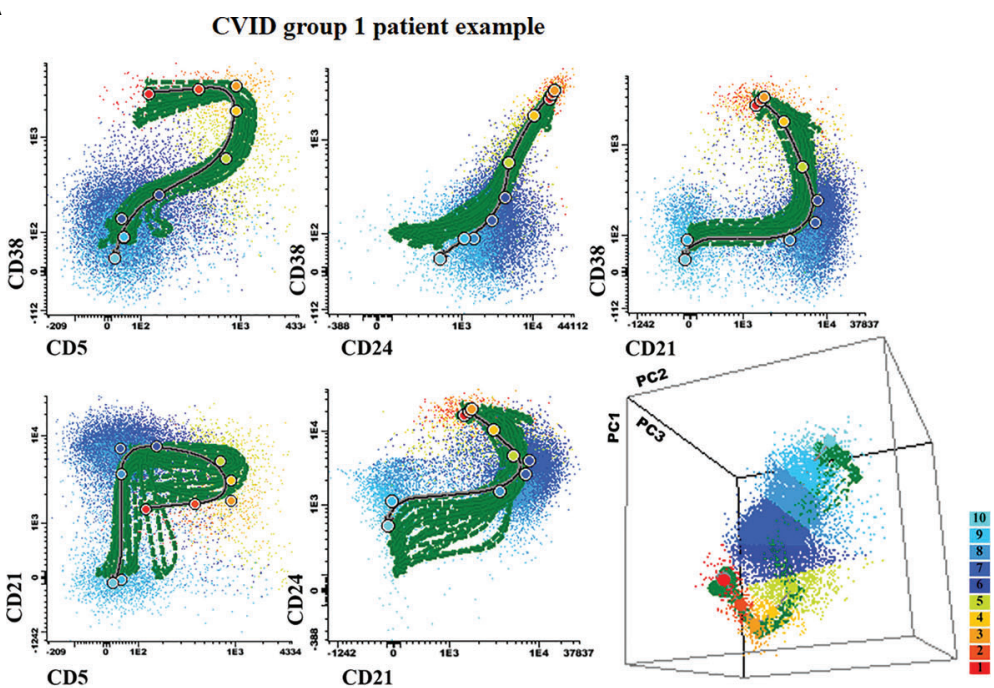

B CVID group 4 patient example
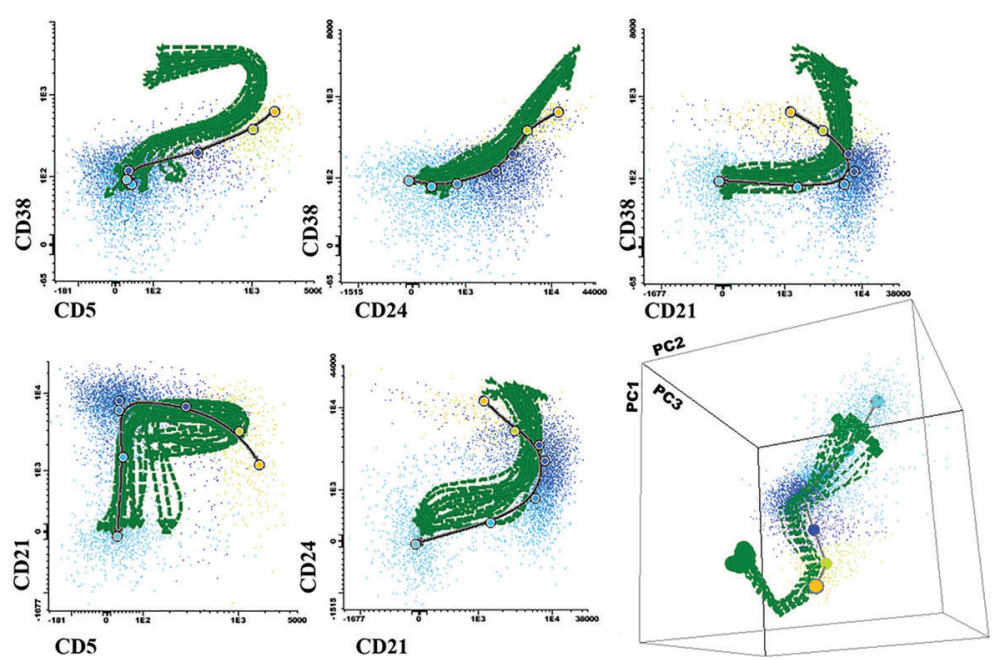

FIGURE 4 | Illustrating 2-dimensional and 3-dimensional dot plot graphical examples of the maturation pathway of pre-GC B-cells in representative Common Variable Immunodeficiency (CVID) patients showing normal-appearing (A; CVID groups 1-3) vs severely disturbed maturation pathways (B; CVID group 4). In all plots, the reference pre-germinal-center (GC) B-cell maturation pathway defined for 18 (individual) HD green lines is shown together with a gray/black line corresponding to the maturation pathway of the two individual CVID patients shown in (A, B), respectively. Colored dots correspond to the median values obtained for the 10 different maturation stages (color code defined in the right) where stage 1 is colored as blue and stage 10 is depicted in red.

CD24- naïve B cell counts ( 8.8 vs 0,74 cells/ $\mu l, p=0.02)$ (Table 1 ). Finally, group 3 included 7/88 (8\%) CVID patients characterized by showing under-expression of CD38 together with higher levels of CD24 at the last stages of maturation of pre-GC Bcells, in line with the underlying increased counts of $\mathrm{CD} 21^{+} \mathrm{CD} 24^{+}$mature naïve $\mathrm{B}$ cells observed among these cases vs. the other CVID patient groups 1 to 3: 137 vs 76,42 , and 59 cells/ $\mu$ in CVID groups 1 , group 2, and group 4, respectively (Table 1).

As referred above, group 4 CVID patients presented clearly altered pre-GC B-cell maturation profiles, the most common alteration (31/31 cases) in their blood pre-GC B-cells consisting of absence/decreased number of cells at the earliest stages of maturation (stages 1-3). In addition, group 4 CVID patients showed abnormally lower counts in blood of $\mathrm{CD}^{-} \mathrm{CD} 38^{++}$ $\mathrm{CD} 21^{\text {het }} \mathrm{CD} 24^{++}-0.36$ vs $0.98,7.6,1.6$, and $0.89 \mathrm{cells} / \mu \mathrm{l}$ in group $1(\mathrm{p}=0.015)$, group $2(\mathrm{p}<0.0001)$ group $3(\mathrm{p}=0.003)$ patients and $\mathrm{HD}(\mathrm{p}=0.004)$, respectively- and $\mathrm{CD}^{+} \mathrm{CD} 38^{++++}$ $\mathrm{CD} 21^{\text {het }} \mathrm{CD} 24^{++}-1.4$ vs $2.6,12$ and 5.6 cells/ $\mu$ l, group $1(\mathrm{p}=0.03)$, group 2, $(\mathrm{p}=0.0117)$ CVID patients and HD $(\mathrm{p}<0.0001)-$, immature/transitional $\mathrm{B}$ cells, together with significantly higher counts of CD21- CD24- -9.9 vs 4, 0.74 cells/ $\mu$ in CVID group 1 


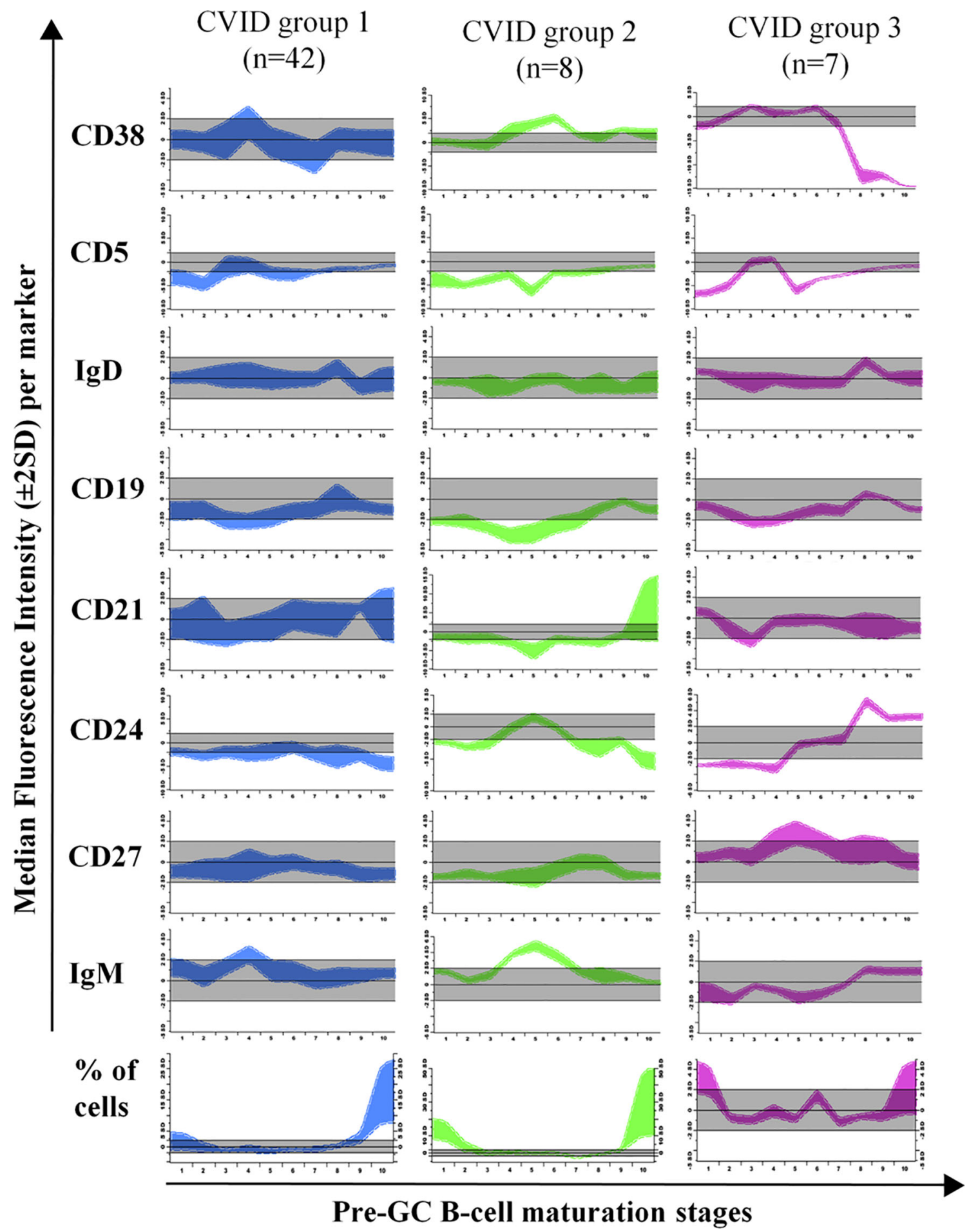

FIGURE 5 | Maturation diagrams per marker of all Common Variable Immunodeficiency (CVID) patients included in each of the three CVID groups of patients displaying a normal-appearing pre-GC maturation profile in blood (groups 1-3). In each diagram the (normalized) reference maturation pathway is shown as a grey area for the \pm 2 SD of normal MFI values per marker. The pre-GC B-cell maturation profile found in CVID patients from each group is displayed as \pm 2 SD bars colorcoded by CVID patient group (CVID group 1 is shown in blue, group 2 in green and group 3 in pink). Values below or above the normal 2SD limit for $\geq 2$ consecutive maturation stages were considered to reflect an altered marker expression profile. 
TABLE 1 | Distribution of different subsets of blood B-cells in HD and CVID patients classified according to the presence of a normal-appearing (CVID groups 1-3) vs severely disturbed maturation pathway (CVID group 4).

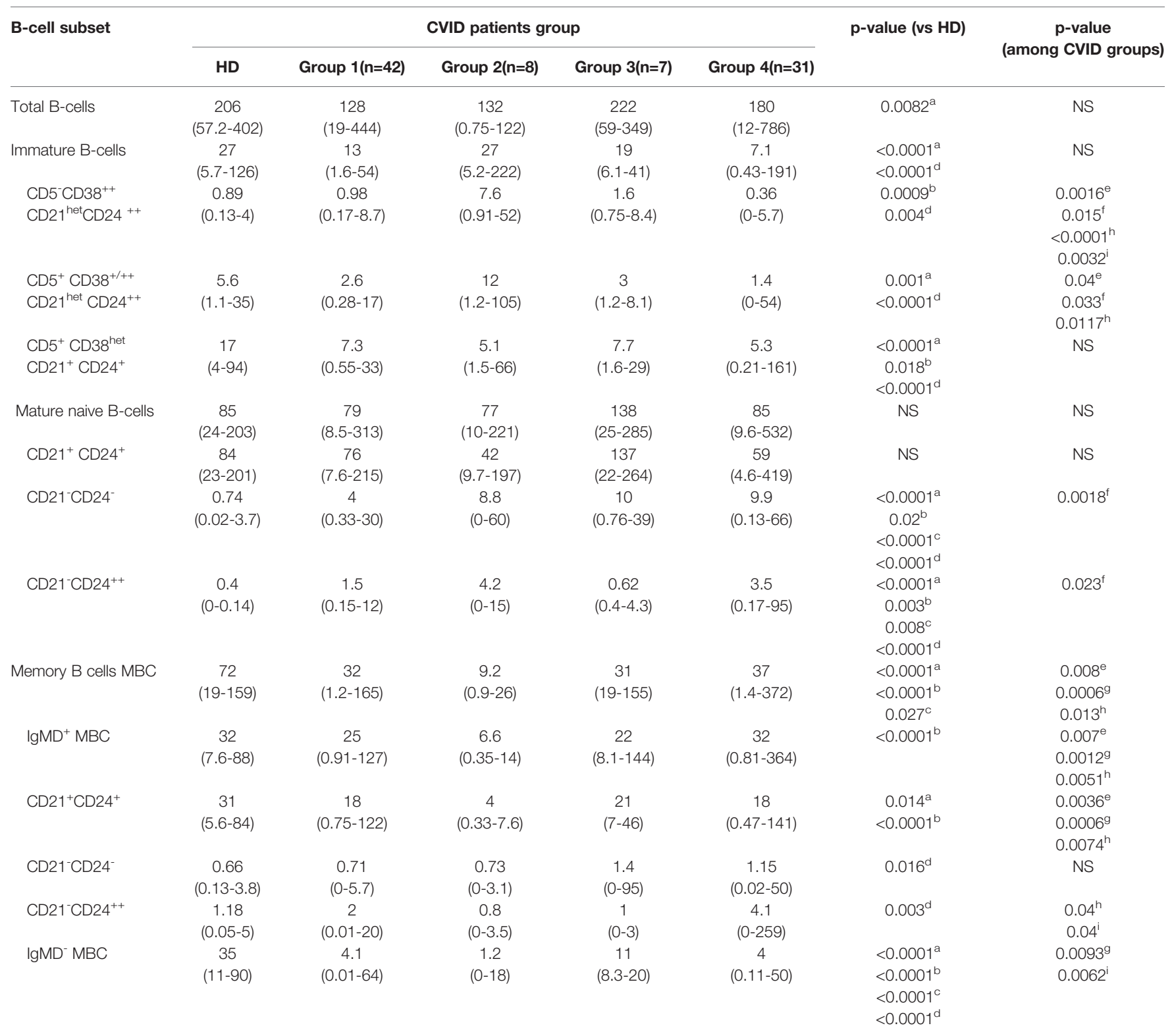

Results expressed as median absolute counts $\left(5^{\text {th }}-95^{\text {th }}\right.$ percentiles) per B-cell subset. The Kruskal-Wallis and Mann-Whitney U tests were used with significance set at $p$-values $<0.05$. NS,

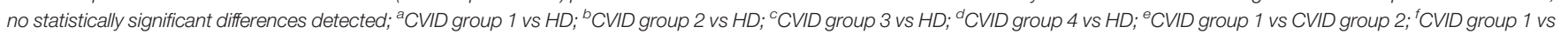
CVID group 4; ${ }^{g}$ CVID group 2 vs CVID group 3; ${ }^{h}$ CVID group 2 vs CVID group 4; ${ }^{C}$ CVID group 3 vs CVID group 4.

cases $(\mathrm{p}=0.0018)$ and $\mathrm{HD},(\mathrm{p}<0.0001)$ respectively- and $\mathrm{CD} 21^{-}$ $\mathrm{CD} 24^{++}$mature naïve $\mathrm{B}$-cells -3.5 vs 1.5 and 0.4 cells/ $\mu$, in group 1 patients $(\mathrm{p}=0.02)$ and $\mathrm{HD},(\mathrm{p}<0.0001)$ respectively-(Table $\mathbf{1})$. In addition, group 4 CVID patients also showed significantly increased blood counts vs HD of CD21- $\mathrm{CD} 24^{-}$(1.15 vs 0.66 cells $/ \mu \mathrm{l}, \mathrm{p}=0.016)$ and $\mathrm{CD} 21^{-} \mathrm{CD}^{++} 4^{++}(4.1 \mathrm{vs} 1.18 \mathrm{cells} / \mu \mathrm{l}$, $\mathrm{p}=0.003) \mathrm{MBC}$ cells, compared to with the other CVID (groups 1-3) cases (Table 1).

From the clinical point of view, no major differences were observed among the patients included in the distinct CVID groups 1 to 4, except for a higher frequency of autoimmune cytopenias in group 4 patients vs. groups $1-3$ cases (23\% vs $6 \%$, $\mathrm{p}=0.032$ ), and a greater prevalence in group 2 patients of lymphadenopathy $(63 \%$ vs. $15 \%, 33 \%, 23 \%$ in group 1,3 , and 4 cases, respectively; $\mathrm{p}=0.03)$ and systemic autoimmunity $(25 \%$ vs. $0 \%, 16 \%$ and $3 \%$ in groups 1,3 , and 4 , respectively; $\mathrm{p}=0.009$ ) (Supplementary Table 3).

\section{DISCUSSION}

CVID is yet a poorly understood, clinically and prognostically heterogeneous disease, whose clinical management remains a challenge. Due to the lack of diagnostic genetic/molecular 
markers in the majority of patients, flowcytometric analysis of lymphocyte populations in blood, in combination with other laboratory data, has become critical for diagnosis and monitoring of CVID. Thus, at present it is well-established that simultaneously decreased plasmablast/plasma cell and/or switched-MBC counts in blood is a hallmark of CVID $(8,9$, 12). Despite pre-GC B-cells appear to be preserved in a substantial proportion of CVID patients, an altered B-cell maturation in bone marrow together with reduced total Bcells, and an expansion of both immature B lymphocytes and $\mathrm{CD} 21^{\text {low }} \mathrm{B}$ cells in blood, have been recurrently reported in a subset of CVID patients $(8,13-16,27,28)$. Here, we investigated in detail the presence and frequency of alterations in both the numerical distribution and the immunophenotypic (maturation) profile of pre-GC B-lymphocytes based on a large cohort of 100 CVID patients from 8 different European centres in comparison to age-matched HD. For this purpose we used the standardized EuroFlow pre-GC B-cell tube and SOP (19-21) together with novel B-cell maturation software tools. Overall our results confirmed the presence of significantly reduced plasmablast/ plasma cell counts in every CVID patient, most frequently associated with decreased switched-MBC. Despite total B-cell counts were significantly reduced in CVID vs age-matched HD, less than a third of all CVID patients investigated here showed abnormally decreased pre-GC B-cell counts in blood, in line with (extensive) previous observations by our and other groups $(8,9)$.

In order to gain further insight into the (potentially) altered pre-GC B-cell profiles in CVID, we dissected the pre-GC compartment into five distinct maturation-associated subsets of pre-GC immature and naïve B-cells. Overall, immature B cells were decreased in almost one third of the patients, while more mature naive B-lymphocytes were found to be below normal levels in only $11 \%$ of cases. Altogether these findings point out a defective $B$ cell production and/or shortened survival of immature B cells (9) in a significant proportion of CVID cases. In line with this hypothesis, more in depth analysis of the immature and naive compartments of pre-GC B-cells showed that while $<10 \%$ of CVID patients had lower counts in blood of the less differentiated $\mathrm{CD}^{-} \mathrm{CD} 38^{++} \mathrm{CD} 21^{\text {het }} \mathrm{CD} 24^{++}$immature B-lymphocytes, more than a third of the cases showed reduced counts of the more differentiated $\mathrm{CD}^{+} \mathrm{CD} 38^{\text {het }} \mathrm{CD} 21^{+} \mathrm{CD} 24^{+}$ immature B-cells. In addition, this maturation blockade at the earliest stages of peripheral immature B-lymphocytes was associated with increased counts of the minor subsets of the more mature $\mathrm{CD} 21^{-}\left(\mathrm{CD} 24^{-}\right.$and $\left.\mathrm{CD} 24^{-++}\right)$naive B-cells in virtually every CVID patient, as also extensively described previously by others in the literature (29-32). Thus, Vlková et al. (33) first reported that CD21 B-lymphocytes expanded in CVID mostly comprise the $\mathrm{CD} 21^{-} \mathrm{CD} 24^{-}$and $\mathrm{CD} 21^{-} \mathrm{CD} 24^{++}$ subsets. Despite the precise functional and clinical significance of both subsets still remains unclear, it has been previously shown that homeostatic stimulation of $\mathrm{CD} 21^{-} \mathrm{B}$-cells induces proliferation of naive B-cells with loss of $\mathrm{CD} 21$ expression and differentiation toward $\mathrm{CD} 21^{-} \mathrm{CD} 24^{-}$and $\mathrm{CD} 21^{-} \mathrm{CD} 24^{++} \mathrm{B}$-cells, in the absence of the classic GC reaction (33). However, in contrast to healthy individuals in whom the majority of $\mathrm{CD} 21^{\text {low }}$
B-cells belong to the MBC compartment $(29,34)$, in CVID patients these cells have not undergone somatic hypermutation and show naïve B-cell features $(35,36)$ in line with our findings. Of note, expanded $\mathrm{CD} 21^{-} \mathrm{B}$-cells have also been associated with T-bet ${ }^{+}$B-cells in humans (37) and with interferon-gamma mediated dysregulation of $\mathrm{B}$ cell maturation induced by follicular helper T cells in CVID (38).

Normal differentiation and survival of immature/transitional and mature naive $\mathrm{B}$-cells requires integration of distinct molecular signals after B-cells are released from the BM to the periphery (39). Thus, almost 40\% immature peripheral blood Bcells produced in human bone marrow may be autorreactive (39, 40); at this stage, peripheral tolerance is checked and only a small percentage of all circulating immature B-lymphocytes will survive the negative selection and become mature naive B-cells (40). Immature B-cells retain low expression levels of BMassociated markers such as CD10, CD38, CD24 (41), and except for the less differentiated immature B-cells that are CD5 negative, they are also $\mathrm{CD}^{+}$. In turn, recent $\mathrm{BM}$ emigrant immature B-cells express high levels of smIgM which contribute to the negative selection based on the $\mathrm{B}$ cell receptor (BCR) affinity for self-antigens (42). Further maturation of immature B-cells and mature naive B-cells is associated with loss of expression of $\mathrm{CD} 38$ and $\mathrm{CD} 5$, and down-regulation of CD24 levels $(41,43-45)$. CD38 has enzymatic activity and modulates peptide concentrations during B-cell signalling, and it is strongly expressed in the GC reaction where it prevents apoptosis of GC B-cells $(43,46)$. CD24 is also highly expressed on immature B-cells and it is associated with Siglec-10 that interacts with SHP-1 phosphatases, a complex implicated in NFKB activation and the prevention of signaling from non-specific antigen receptors (47). In turn, the $\mathrm{CD} 21$ complement receptor is part of the BCR co-receptor complex (CD19, CD21, CD81, and CD225) (48), that acts as positive regulator of antigen-mediated BCR signaling, a critical event for normal maturation of transitional B-cells (39) into naïve B-lymphocytes, and the differentiation of the later cells to $\mathrm{MBC}$ and plasma cells. Thus, $\mathrm{CD} 21$ reduces the B-cell activation threshold and contributes to amplification of BCR signaling (30). In contrast, $\mathrm{CD} 5$ is a negative regulator of $\mathrm{BCR}$ signaling that limits B-cell activation to avoid autorreactivity during the early steps of B-cell maturation in blood, while contributing to upregulate the BCR/TCR activation threshold after antigen recognition $(44,49,50)$. Consequently, high levels of CD5 expression together with low CD21 expression on immature Bcells, avoid autorreactivity (43). Altogether, these findings support the notion that transitional/immature B-cells are particularly sensitive to subtle variations in stimuli and signals that determine cell death vs survival, on a delicate equilibrium that avoids excessive auto-reactivity while ensuring production of a sufficiently wide BCR repertoire, via further differentiation to mature naive B-lymphocytes. In addition, our findings about an altered numerical distribution of distinct maturation-associated subsets of immature B-cells and mature naive B-lymphocytes in CVID, suggest potential (co)existence of maturation blockades at the earliest stages of maturation of peripheral immature B- 
lymphocytes, with an abnormally increased differentiation toward less reactive $\mathrm{CD} 21^{-}$naive $\mathrm{B}$-cells, that might finally lead to decreased plasma cell and switched memory B-cell counts in these patients. If this hypothesis holds true, an altered maturation of pre-GC B-cells would also be a hallmark of CVID, even among patients that show normal pre-GC Bcell counts.

In order to investigate in more depth the potential existence of an altered maturation of pre-GC B-cells in CVID toward CD $21^{-}$ naïve $\mathrm{B}-$ lymphocytes, we built a normal (reference) database to trace the maturation of pre-GC B-lymphocytes from the less differentiated transitional/immature to the more mature naive $\mathrm{B}$ cells. As expected, the normal (HD) database, showed that CD38, $\mathrm{CD} 5, \mathrm{CD} 24$, and smIgM are downregulated in the transition between immature/transitional B-cells and mature naive Blymphocytes, in line with previous observations $(42,43)$. In contrast, comparison of individual CVID patients against the normal reference pre-GC B-cell maturation pathway, revealed altered marker expression profiles in every CVID patient analyzed, including four clearly different patterns of alteration. Thus, in around one third of the cases (CVID group 4) reduced numbers of immature/transitional B-cell subsets associated with increased counts of $\mathrm{CD} 21^{-}$naïve and unswitched $\mathrm{MBC}$ were found to be the consequence of a completely deregulated pre-GC B-cell maturation associated also with immunophenotypes for one or more markers that deviated significantly from those of normal pre-GC B-cells. Of note, among CVID group 4 patients, the altered immunophenotypic pre-GC B-cell maturation profiles and preGC B-cell counts were associated with a significantly higher frequency of systemic autoimmunity, as also reported by others (51), suggesting a potential failure of the negative selection of immature B-cells in BM, and a parallel attempt to keep B-cell production (and mature $\mathrm{B}$-cell numbers) within the normal range. In contrast, pre-GC B-cell counts were less severely reduced in the other three CVID patient groups here identified, in line with the observation in these groups of patients of more conserved, normally-appearing, pre-GC B-cell maturation profiles. Despite this, multiple alterations on the expression levels of specific cell surface molecules along the pre-GC B-cell maturation pathway were observed in these patients, particularly in the CVID group 2 and group 3 here identified.

Similarly to CVID group 4 cases, group 1, and particularly group 2 CVID patients displayed overexpression of smIgM at intermediate stages of maturation of blood pre-GC B-cells, in association with significantly reduced switched MBC. In contrast, CVID group 3 cases showed both normal smIgM expression levels and closer to normal IgMD $^{-} \mathrm{MBC}$ counts. Downregulation of smIgM expression levels in B-cells at the latest stage of pre-GC B-cell maturation is required for further negative selection of autorreactive B-lymphocytes and adequate B-cell maturation. Thus, the overexpression of SIgM here observed might contribute to explain the higher frequency of autoimmune diseases in CVID group 2 patients, in line with previous findings by Warnatz et al. (27) in a subset (type Ia) of CVID patients, and also findings of other groups that showed high expression levels of smIgM and autoimmunity in PID other than CVID, reflecting B-cell activation (52) in these patients. This, together with the presence of higher levels of CD38 at intermediate stages of maturation of pre-GC B-cells, (which was also more pronounced in CVID group 2 patients), may reflect delayed maturation of immature B-cells to mature naive Blymphocytes among this subgroup of CVID patients. This may contribute to explain why compared to the other CVID groups, CVID group 2 cases were also those who presented the highest counts of the more immature $\left(\mathrm{CD}^{-} \mathrm{CD} 38^{++} \mathrm{CD} 21^{\text {het }} \mathrm{CD} 24^{++}\right)$ blood B-cells. In parallel, lower levels of CD5 (found in common in the three CVID groups 1 to 3 ) together with a marked reduction of the amount of CD19 expressed/B-cell, particularly in CVID group 2 cases, may further affect the activation threshold (53) required for BCR-mediated B-cell activation and subsequent maturation of immature and naive B-lymphocytes to MBC and plasma cells in this group of CVID patients. In fact, reduced CD5 expression during pre-GC maturation might lower the BCR activation threshold responsible for the activation of autorreactive B-cells. This together with the increased numbers of CD21- naïve B-cells would contribute to a lower B-cell (activation) response (36), leading to a more pronounced anergic state, as previously associated with $\mathrm{CD} 21^{- \text {llow }} \mathrm{B}$ cells in CVID $(29,30)$ and CD19-CD81 complex immunodeficiency (48), together with downregulation of B-cell activation receptors in parallel to upregulation of genes involved in the inhibition of B-cell proliferation (35). Interestingly, CVID group 2 cases showed partially overlapping clinical and immunological features to CVID Ia patients who are defined by coexistence of strongly decreased $\mathrm{MBC}$ and expanded CD21 ${ }^{\text {low }}$ B-lymphocytes, and show a unique clinical behaviour with greater frequency (vs CVID Ib and II cases) of autoimmunity and organomegalies (8, 27). Despite these similarities, in our patients expanded CD $21^{-}$ pre-GC B-cells were not exclusively detected among CVID group 2 patients, but they were also found in other patient groups, particularly in CVID group 4 cases. Further studies are required to better understand the relationship that might exist between both CVID patient groups.

In summary, detailed analysis of the maturation profile of pre-GC B-cells in CVID compared to normal blood B-cells, based on the Euroflow Pre-GC B-cell tube and maturation software tools, revealed systematically altered marker expression immunophenotypic profiles in CVID, in association with decreased pre-GC B-cell counts, with up to four distinctly altered profiles. Further studies in larger cohorts of CVID patients with longer follow-up are needed to confirm our results, and to correlate the distinct immune profiles here described with the underlying CVID-associated monogenic mutations and polygenic variant profiles, intravenous Ig therapy and patient outcome.

\section{DATA AVAILABILITY STATEMENT}

The original contributions presented in the study are included in the article/Supplementary Material. Further inquiries can be directed to the corresponding authors. 


\section{ETHICS STATEMENT}

The studies involving human participants were reviewed and approved by the local Ethics Committees of the participating centers: Hospital Universitario La Paz, Madrid, Spain (PI-2833 and 2009/3348/I); Charles University, Prague, Czech Republic (15-28541A); Erasmus MC, Rotterdam, The Netherlands (MEC013-026); St Anne's University, Brno, Czech Republic (METC 1G2015); BRC-Translational Immunology Lab, University of Oxford, Oxford, United Kingdom; University of Salamanca, Salamanca, Spain (USAL/CSIC 20-02-2013); University Hospital of Ghent, Belgium (B670201523515); and Faculdade de Medicina da Universidade de Lisboa and Centro Hospitalar Universitário Lisboa Norte, Lisbon, Portugal (937/13). The patients/participants provided their written informed consent to participate in this study.

\section{AUTHOR CONTRIBUTIONS}

EL-G, MB, TK, JP, AS, AO, and JD contributed to the conception and design of the study. LP-M, JTC, MP-A, EB, MW, CB, JN, $\mathrm{TM}$, and A-KK performed data acquisition and patient data collection. LP-M, JTC, and MP-A performed data analysis. LP-M

\section{REFERENCES}

1. Bonilla FA, Barlan I, Chapel H, Costa-Carvalho BT, Cunningham-Rundles C, de la Morena MT, et al. International Consensus Document (ICON): Common Variable Immunodeficiency Disorders. J Allergy Clin Immunol Pract (2016) 4:38-59. doi: 10.1016/j.jaip.2015.07.025

2. Picard C, Bobby Gaspar H, Al-Herz W, Bousfiha A, Casanova J-L, Chatila T, et al. International Union of Immunological Societies: 2017 Primary Immunodeficiency Diseases Committee Report on Inborn Errors of Immunity. J Clin Immunol (2018) 38(1):96-128. doi: 10.1007/s10875-0170464-9

3. Bousfiha A, Jeddane 1, Picard C, Ailal F, Bobby Gaspar H, Al-Herz W, et al. The 2017 IUIS Phenotypic Classification for Primary Immunodeficiencies. J Clin Immunol (2018) 38(1):129-43. doi: 10.1007/s10875-017-0465-8

4. Odnoletkova I, Kindle G, Quinti I, Grimbacher B, Knerr V, Gathmann B, et al. The burden of common variable immunodeficiency disorders: a retrospective analysis of the European Society for Immunodeficiency (ESID) registry data. Orphanet J Rare Dis (2018) 13(1):201. doi: 10.1186/s13023-018-0941-0

5. Chapel H, Lucas M, Lee M, Bjorkander J, Webster D, Grimbacher B, et al. Common Variable immunodeficiency disorders: Division into distinct clinical phenotypes. Blood (2008) 112(2):277-86. doi: 10.1182/blood-2007-11-124545

6. de Valles-Ibáñez G, Esteve-Sole A, Piquer M, González-Navarro A, Hernández-Rodríguez $\mathrm{J}$, Laayouni $\mathrm{H}$, et al. Evaluating the genetics of common variable immunodeficiency: monogenetic model and beyond. Front Immunol (2018) 9:636. doi: 10.3389/fimmu.2018.00636

7. del Pino-Molina L, Rodríguez-Ubreva J, Torres Canizales J, Coronel-Díaz M, Kulis M, Martín-Subero JL, et al. Impaired CpG Demethylation in Common Variable Immunodeficiency Associates With B Cell Phenotype and Proliferation Rate. Front Immunol (2019) 10:1-11. doi: 10.3389/fimmu. 2019.00878

8. Wehr C, Kivioja T, Schmitt C, Ferry B, Witte T, Eren E, et al. The EUROclass trial: Defining subgroups in common variable immunodeficiency. Blood (2008) 111(1):77-85. doi: 10.1182/blood-2007-06-091744

9. Driessen GJ, Van Zelm MC, Van Hagen PM, Hartwig NG, Trip M, Warris A, et al. B-cell replication history and somatic hypermutation status identify and QL built the pre-GC B-cell maturation database uploaded in Infinicyt. LP-M, EL-G, and AO wrote the manuscript. All authors contributed to the article and approved the submitted version.

\section{FUNDING}

The coordination and innovation processes of this study were supported by the EuroFlow Consortium (Chairmen: MB and AO). LP-M was supported by FIS PI16/01605 and JTC by FIS PI13/02296 (Fondo de Investigación Sanitaria Instituto de Salud Carlos III, Madrid, Spain). The work was partially supported by grant PI20/01712-FEDER (Fondo de Investigación Sanitaria Instituto de Salud Carlos III, Madrid, Spain) and a grant from Fundación Mutua Madrileña (MMA, Madrid, Spain).

\section{SUPPLEMENTARY MATERIAL}

The Supplementary Material for this article can be found online at: https://www.frontiersin.org/articles/10.3389/fimmu.2020.603972/ full\#supplementary-material distinct pathophysiologic backgrounds in common variable immunodeficiency. Blood (2011) 118(26):6814-23. doi: 10.1182/blood2011-06-361881

10. Kalina T, Stuchlý J, Janda A, Hrušák $O$, Rủžičková Š, Šedivá A, et al. Profiling of polychromatic flow cytometry data on B-cells reveals patients' clusters in common variable immunodeficiency. Cytom Part A (2009) 75(11):902-9. doi: 10.1002/cyto.a.20801

11. Seidel MG, Kindle G, Gathmann B, Quinti I, Buckland M, van Montfrans J, et al. The European Society for Immunodeficiencies (ESID) Registry Working Definitions for the Clinical Diagnosis of Inborn Errors of Immunity. J Allergy Clin Immunol Pract (2019) 7(6):1763-70. doi: 10.1016/j.jaip.2019.02.004

12. Blanco E, Pérez-Andrés M, Arriba-Méndez S, Serrano C, Criado I, Del PinoMolina L, et al. Defects in memory B-cell and plasma cell subsets expressing different immunoglobulin-subclasses in patients with CVID and immunoglobulin subclass deficiencies. J Allergy Clin Immunol (2019) 144 (3):809-24. doi: 10.1016/j.jaci.2019.02.017

13. Gomes Ochtrop ML, Goldacker S, May AM, Rizzi M, Draeger R, Hauschke D, et al. T and B lymphocyte abnormalities in bone marrow biopsies of common variable immunodeficiency. Blood (2011) 118(2):309-18. doi: 10.1182/blood2010-11-321695

14. Troilo A, Wehr C, Janowska I, Venhoff N, Thiel J, Rawluk J, et al. Nonpermissive bone marrow environment impairs early B-cell development in common variable immunodeficiency. Blood (2020) 135 (17):1452-7. doi: 10.1182/blood.2019003855

15. Anzilotti C, Kienzler AK, Lopez-Granados E, Gooding S, Davies B, Pandit H, et al. Key stages of bone marrow B-cell maturation are defective in patients with common variable immunodeficiency disorders. J Allergy Clin Immunol (2015) 136(2):487-90. doi: 10.1016/j.jaci.2014.12.1943

16. Quinti I, Keller B, Driessen G, Fisch P, Salzer U, Peter H-H, et al. Circulating CD21low B cells in common variable immunodeficiency resemble tissue homing, innate-like B cells. Proc Natl Acad Sci (2009) 106(32):13451-6. doi: 10.1073/pnas.0901984106

17. Wentink MWJ, Kalina T, Perez-Andres M, del Pino Molina L, IJspeert H, Kavelaars FG, et al. Delineating Human B Cell Precursor Development With Genetically Identified PID Cases as a Model. Front Immunol (2019) 10:1-12. doi: $10.3389 /$ fimmu.2019.02680 
18. Pedreira CE, da Costa ES, Lecrevise Q, Grigore G, Fluxa R, Verde J, et al. From big flow cytometry datasets to smart diagnostic strategies: The EuroFlow approach. J Immunol Methods (2019) 475:112631. doi: 10.1016/j.jim.2019.07.003

19. Orfao A, Matarraz S, Pérez-andrés M, Almeida J, Teodosio C, Berkowska MA, et al. Immunophenotypic dissection of normal hematopoiesis. J Immunol Methods (2019) 475:112684. doi: 10.1016/j.jim.2019.112684

20. van Dongen JJM, van der Burg M, Kalina T, Perez-Andres M, Mejstrikova E, Vlkova M, et al. EuroFlow-Based Flowcytometric Diagnostic Screening and Classification of Primary Immunodeficiencies of the Lymphoid System. Front Immunol (2019) 10:1-21. doi: 10.3389/fimmu.2019.01271

21. Kalina T, Flores-Montero J, Van Der Velden VHJ, Martin-Ayuso M, Böttcher S, Ritgen M, et al. EuroFlow standardization of flow cytometer instrument settings and immunophenotyping protocols. Leukemia (2012) 26(9):1986-2010. doi: 10.1038/leu.2012.122

22. Van Der Burg M, Kalina T, Perez-Andres M, Vlkova M, Lopez-Granados E, Blanco E, et al. The EuroFlow PID orientation tube for flow cytometric diagnostic screening of primary immunodeficiencies of the lymphoid system. Front Immunol (2019) 10:246. doi: 10.3389/fimmu.2019.00246

23. Flores-Montero J, Sanoja-Flores L, Paiva B, Puig N, Garcia-Sanchez O, Bottcher S, et al. Next Generation Flow for highly sensitive and standardized detection of minimal residual disease in multiple myeloma. Leukemia (2017) 31(10):2094-103. doi: 10.1038/leu.2017.29

24. Ameratunga R, Brewerton M, Slade C, Jordan A, Gillis D, Steele R, et al. Comparison of diagnostic criteria for common variable immunodeficiency disorder. Front Immunol (2014) 5:415. doi: 10.3389/fimmu.2014.00415

25. Flores-montero J, Grigore G, Fluxá R, Hernández J, Fernandez P, Almeida J, et al. EuroFlow Lymphoid Screening Tube (LST ) data base for automated identification of blood lymphocyte subsets. J Immunol Methods (2019) 475:112662. doi: 10.1016/j.jim.2019.112662

26. Blanco E, Pérez-Andrés M, Arriba-Méndez S, Contreras-Sanfeliciano T, Criado I, Pelak O, et al. Age-associated distribution of normal B-cell and plasma cell subsets in peripheral blood. J Allergy Clin Immunol (2018) 141:2208-2219.e16. doi: 10.1016/j.jaci.2018.02.017

27. Warnatz K, Denz A, Dräger R, Braun M, Groth C, Wolff-Vorbeck G, et al. Severe deficiency of switched memory B cells (CD27+IgM-IgD-) in subgroups of patients with common variable immunodeficiency: A new approach to classify a heterogeneous disease. Blood (2002) 99:1544-51. doi: 10.1182/blood.V99.5.1544

28. Piqueras B, Lavenu-Bombled C, Galicier L, Bergeron-van der Cruyssen F, Mouthon L, Chevret S, et al. Common variable immunodeficiency patient classification based on impaired B cell memory differentiation correlates with clinical aspects. J Clin Immunol (2003) 23(5):385-400. doi: 10.1023/ a:1025373601374

29. Pupovac A, Good-Jacobson KL. An antigen to remember: regulation of B cell memory in health and disease. Curr Opin Immunol (2017) 45:89-96. doi: 10.1016/j.coi.2017.03.004

30. Thorarinsdottir K, Camponeschi A, Gjertsson I, Mårtensson IL. CD21-/low B cells: A Snapshot of a Unique B Cell Subset in Health and Disease. Scand J Immunol (2015) 82(3):254-61. doi: 10.1111/sji.12339

31. Proschan MA, Kottilil S, Fauci AS, Roby G, Arthos J, Malaspina A, et al. Evidence for HIV-associated B cell exhaustion in a dysfunctional memory B cell compartment in HIV-infected viremic individuals. J Exp Med (2008) 205 (8):1797-805. doi: 10.1084/jem.20072683

32. Rakhmanov M, Gutenberger S, Keller B, Schlesier M, Peter HH, Warnatz K. CD21low B cells in common variable immunodeficiency do not show defects in receptor editing, but resemble tissue-like memory B cells. Blood (2010) 116 (18):3682-3. doi: 10.1182/blood-2010-05-285585

33. Vlková M, Froňková E, Kanderová V, Janda A, Růžiková Š, Litzman J, et al. Characterization of Lymphocyte Subsets in Patients with Common Variable Immunodeficiency Reveals Subsets of Naive Human B Cells Marked by CD24 Expression. J Immunol (2010) 185(11):6431-8. doi: 10.4049/jimmunol.0903876

34. Kurosaki T, Kometani K, Ise W. Memory B cells. Nat Rev Immunol (2015) 15:149-59. doi: 10.1038/nri3802

35. Isnardi I, Ng Y, Menard L, Meyers G, Saadoun D, Srdanovic I, et al. Complement receptor 2/CD21. Blood (2016) 115:5026-37. doi: 10.1182/ blood-2009-09-243071

36. Thorarinsdottir K, Camponeschi A, Cavallini N, Grimsholm O, Jacobsson L, Gjertsson I, et al. CD21-/low B cells in human blood are memory cells. Clin Exp Immunol (2016) 185:252-62. doi: 10.1111/cei.12795
37. Knox JJ, Myles A, Cancro MP. T-bet(+) memory B cells: Generation, function, and fate. Immunol Rev (2019) 288:149-60. doi: 10.1111/imr.12736

38. Unger S, Seidl M, van Schouwenburg P, Rakhmanov M, Bulashevska A, Frede N, et al. The $\mathrm{T}(\mathrm{H}) 1$ phenotype of follicular helper $\mathrm{T}$ cells indicates an IFN- $\gamma$ associated immune dysregulation in patients with CD21low common variable immunodeficiency. J Allergy Clin Immunol (2018) 141:730-40. doi: 10.1016/ j.jaci.2017.04.041

39. Thomas MD, Srivastava B, Allman D. Regulation of peripheral B cell maturation. Cell Immunol (2006) 239:92-102. doi: 10.1016/j.cellimm.2006.04.007

40. Looney RJ, Palanichamy A, Sanz I, Barnard J, Owen T, Quach T, et al. Novel Human Transitional B Cell Populations Revealed by B Cell Depletion Therapy. J Immunol (2009) 182:5982-93. doi: 10.4049/jimmunol.0801859

41. Yu LJ, Shaw PJ, Cuss AK, Cannons JL, Tangye SG, Nichols KE, et al. Expansion of Functionally Immature Transitional B Cells Is Associated with Human-Immunodeficient States Characterized by Impaired Humoral Immunity. J Immunol (2014) 176:1506-16. doi: 10.4049/jimmunol.176.3.1506

42. Benschop RJ, Brandl E, Chan AC, Cambier JC. Unique Signaling Properties of B Cell Antigen Receptor in Mature and Immature B Cells: Implications for Tolerance and Activation. J Immunol (2001) 167:4172-9. doi: 10.4049/ jimmunol.167.8.4172

43. Perez-Andres M, Paiva B, Nieto G, Caraux A, Schmitz A, Almeida J, et al. Human peripheral blood B-Cell compartments: A crossroad in B-cell traffic. Cytom Part B Clin Cytom (2010) 78:47-60. doi: 10.1002/cyto.b.20547

44. Lipsky PE, Fischer R, Chang S, Kuchen S, Lee J. Identification and Characterization of a Human CD5+ Pre-Naive B Cell Population. J Immunol (2009) 182:4116-26. doi: 10.4049/jimmunol.0803391

45. Santner-Nanan B, Tangye SG, Nanan R, Wong M, Suryani S, Williams A, et al. Differential expression of CD21 identifies developmentally and functionally distinct subsets of human transitional B cells. Blood (2009) 115 (3):519-29. doi: 10.1182/blood-2009-07-234799

46. Saxon A, Keld B, Guo B, Hart NST, Lyon L. B cells from a distinct subset of patients with common variable CD38 expression, and undergo enhanced apoptosis. Clin Exp Immunol (1995) 95:17-25. doi: 10.1111/j.1365-2249.1995.tb06630.x

47. Liu Y, Chen GY, Zheng P. CD24-Siglec G/10 discriminates danger- from pathogen-associated molecular patterns. Trends Immunol (2009) 30(12):55761. doi: 10.1016/j.it.2009.09.006

48. Wentink MWJ, van Zelm MC, van Dongen JJM, Warnatz K, van der Burg M. Deficiencies in the CD19 complex. Clin Immunol (2018) 195:82-7. doi: 10.1016/j.clim.2018.07.017

49. Dalloul A. CD5: A safeguard against autoimmunity and a shield for cancer cells. Autoimmun Rev (2009) 8:349-53. doi: 10.1016/j.autrev.2008.11.007

50. Artac H, Reisli I, Kara R, Pico-Knijnenburg I, Adin-Çinar S, Pekcan S, et al. Bcell maturation and antibody responses in individuals carrying a mutated CD19 allele. Genes Immun (2010) 11(7):523-30. doi: 10.1038/gene.2010.22

51. Warnatz K, Wehr C, Dräger S, Schmidt S, Eibel H, Schlesier M, et al. Expansion of CD19(hi)CD21(lo/neg) B cells in common variable immunodeficiency (CVID) patients with autoimmune cytopenia. Immunobiology (2002) 206(5):502-13. doi: 10.1078/0171-2985-00198

52. Picchianti Diamanti A, Rosado MM, Scarsella M, Ceccarelli S, Laganà B, D'Amelio R, et al. Increased serum IgM, immunodeficiency, and autoimmunity: A clinical series. Int J Immunopathol Pharmacol (2015) 28 (4):547-56. doi: 10.1177/0394632015600231

53. Li X, Ding Y, Zi M, Sun L, Zhang W, Chen S, et al. CD19, from bench to bedside. Immunol Lett (2017) 183:86-95. doi: 10.1016/j.imlet.2017.01.010

Conflict of Interest: JD, MB, TK, MP-A, EL-G, A-KK, EB, and AO each report being one of the inventors on the EuroFlow-owned patent PCT/NL 2015/050762 (Diagnosis of primary immunodeficiencies), which is licensed to Cytognos, a company that pays royalties to the EuroFlow Consortium.

Copyright (C) 2021 del Pino-Molina, López-Granados, Lecrevisse, Torres Canizales, Pérez-Andrés, Blanco, Wentink, Bonroy, Nechvatalova, Milota, Kienzler, Philippé, Sousa, van der Burg, Kalina, van Dongen and Orfao. This is an open-access article distributed under the terms of the Creative Commons Attribution License (CC BY). The use, distribution or reproduction in other forums is permitted, provided the original author(s) and the copyright owner(s) are credited and that the original publication in this journal is cited, in accordance with accepted academic practice. No use, distribution or reproduction is permitted which does not comply with these terms. 